\title{
Hydrate-Based Methane Separation from the Drainage Coal-Bed Methane with Tetrahydrofuran Solution in the Presence of Sodium Dodecyl Sulfate
}

\author{
Xiao-Sen Li, ${ }^{*}{ }^{\dagger, \ddagger}$ Jing Cai, ${ }^{\dagger, \ddagger}$ Zhao-Yang Chen, ${ }^{\dagger, \ddagger}$ and Chun-Gang $\mathrm{Xu}^{\dagger, \dagger, \S}$ \\ ${ }^{\dagger}$ Key Laboratory of Renewable Energy and Gas Hydrate, Guangzhou Institute of Energy Conversion, and ${ }^{\ddagger}$ Guangzhou Center for Gas \\ Hydrate Research, Chinese Academy of Sciences, Guangzhou 510640, P. R. China \\ ${ }^{\S}$ Graduate University of Chinese Academy of Sciences, Beijing 100083, P. R. China
}

ABSTRACT: To determine the appropriate operating conditions for separating methane $\left(\mathrm{CH}_{4}\right)$ from drainage coal-bed methane $(\mathrm{CBM})$ mixed with air, a hydrate-based methane separation method is proposed. The amount of gas uptake, $\mathrm{CH}_{4}$ concentration in decomposed gas phase, $\mathrm{CH}_{4}$ split fraction, and $\mathrm{CH}_{4}$ separation factor are investigated at the initial operating pressure range of $1.50-4.50 \mathrm{MPa}$ and $279.15 \mathrm{~K}$ in the presence of sodium dodecyl sulfate (SDS) with the concentration range of 0-1000 ppm in $1.0 \mathrm{~mol} \%$ tetrahydrofuran (THF) aqueous solution. The results indicate that the $1.0 \mathrm{~mol} \%$ THF aqueous solution with the addition of $300 \mathrm{ppm}$ SDS at $2.50 \mathrm{MPa}$ and $279.15 \mathrm{~K}$ is the optimal condition for recovering $\mathrm{CH}_{4}$ from the drainage $\mathrm{CBM}$ via hydrate formation. Under the condition, the final amount of the gas uptake, the $\mathrm{CH}_{4}$ concentration in decomposed gas phase, the $\mathrm{CH}_{4}$ split fraction, and the $\mathrm{CH}_{4}$ separation factor after a one-stage hydrate-based separation are up to $0.1364 \mathrm{~mol}, 69.93 \mathrm{~mol} \%, 86.44 \%$, and 10.77, respectively. The result illustrates that the hydrate-based $\mathrm{CH}_{4}$ separation is a promising method to recover $\mathrm{CH}_{4}$ from the drainage $\mathrm{CBM}$ at mild conditions. Moreover, $\mathrm{CH}_{4}$ recovered from the drainage $\mathrm{CBM}$ can be directly utilized in industry.

\section{INTRODUCTION}

Coal-bed methane (CBM), mainly consisting of methane $\left(\mathrm{CH}_{4}\right)$, is a significant source of clean energy with a significant resources in China. The reserves of the CBM resource buried to a depth of $2000 \mathrm{~m}$ is more than 34 trillion cubic meters, ranking third in the world. ${ }^{1}$ It exists in three forms in the coal seams: absorbed in the porous media, free in the fracture, and dissolving in the underwater of coal bed. ${ }^{2}$ Thus, there are two principles to exploit CBM, such as discharging water ${ }^{3,4}$ and replacing with carbon dioxide $\left(\mathrm{CO}_{2}\right){ }^{5}$ Due to the complicated coal seam occurrence conditions, reservoir geological conditions, coal distribution, etc., discharging water is most widely applied to collect CBM through the extraction system of coal mines. ${ }^{6}$ Accordingly, the exploited $\mathrm{CBM}$ is called drainage $\mathrm{CBM}$ with a low and unstable concentration of $\mathrm{CH}_{4}$ mixed with air. Consequently, such drawbacks lead to the difficulties and risks for the subsequent processes of disposing the drainage CBM. Thus, the drainage CBM can only be emitted into the atmosphere to ensure the safety of coal mining. As a result, a large amount of potential clean resources are wasted, and the environment is contaminated. In China, the amount of CBM discharged into the atmosphere is approximately 1.94 billion cubic meters per year, ranking first in the world. ${ }^{7}$ Therefore, it is necessary to undertake research on separating and recovering $\mathrm{CH}_{4}$ from the drainage CBM.

However, the $\mathrm{CH}_{4}$ concentration in drainage $\mathrm{CBM}$ is as low as $15-60 \mathrm{~mol} \%$ and can even be lower than $15 \mathrm{~mol} \%{ }^{8}$ Drainage $\mathrm{CBM}$ can not be utilized directly in industry as natural gas unless the $\mathrm{CH}_{4}$ concentration in the $\mathrm{CBM}$ is higher than $90 \mathrm{~mol} \%$. After the pretreatments of sulfur removal, desiccation, and deoxygenation, the drainage CBM mainly contains $\mathrm{CH}_{4}$ and $\mathrm{N}_{2}$. Consequently, the recovery of $\mathrm{CH}_{4}$ from the drainage $\mathrm{CBM}$ is focused on the separation of $\mathrm{CH}_{4}$ from the $\mathrm{CH}_{4} / \mathrm{N}_{2}$ gas mixture. At present, the technologies of separating the $\mathrm{CH}_{4} / \mathrm{N}_{2}$ gas mixture contain cryogenic fractionation, pressure swing absorption, and membrane separation. However, those technologies can not recover $\mathrm{CH}_{4}$ from the drainage CBM effectively due to the limitations of cost and security on facility and operating process. ${ }^{9}$ For example, the cryogenic fractionation technology can not ensure the stable operating condition for the variation of the $\mathrm{CH}_{4}$ concentration in the drainage $\mathrm{CBM}$, which requires changing the refrigerant composition to obtain a better $\mathrm{CH}_{4}$ separation efficiency. The pressure swing absorption technology can not achieve a high $\mathrm{CH}_{4}$ separation efficiency for the limitation of the absorbent, which has a close separation factor and little difference in absorbing capacity between $\mathrm{CH}_{4}$ and $\mathrm{N}_{2}$. Although the membrane separation technology has the advantage of simple craft and easy operation, it requires a huge cost of membrane materials. The above traditional gas separation technologies are not utilized widely in the industry to concentrate $\mathrm{CH}_{4}$ from the drainage CBM. Therefore, an alterative safe and efficient way is required to recover $\mathrm{CH}_{4}$ from the drainage CBM simulation gas (the $\mathrm{CH}_{4} / \mathrm{N}_{2}$ gas mixture). The hydrate-based separation is a potential technology to achieve the separation purpose.

The basis of the hydrate-based separation is the selective partition of the target component between the hydrate phase and the gaseous phase. Recently, the hydrate-based separation technology is generally applied to recover $\mathrm{CO}_{2}$ from flue and

Received: November 17, 2011

Revised: January 18, 2012

Published: January 25, 2012 


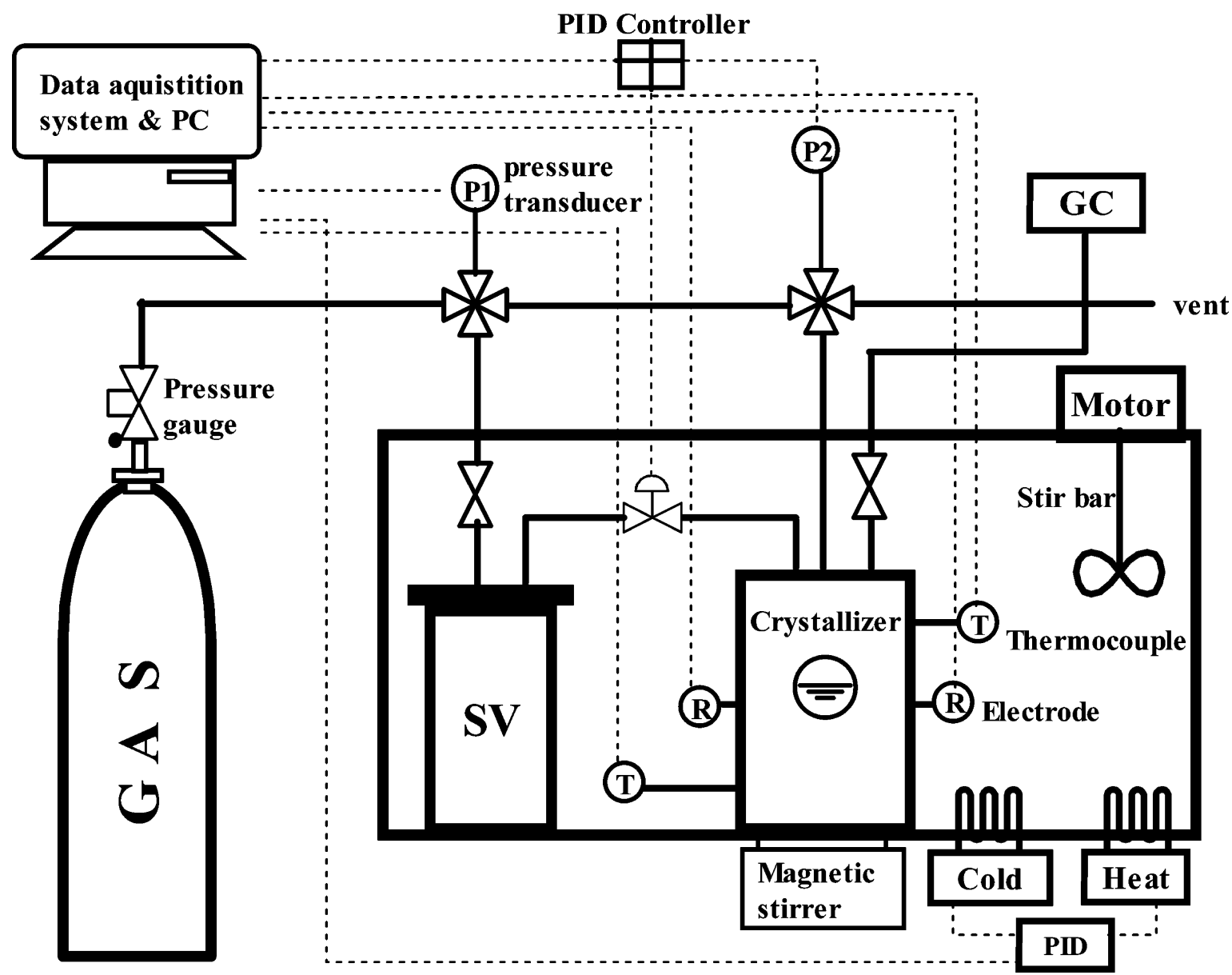

Figure 1. Experimental apparatus: CR, crystallizer; SV, supply vessel; T, thermo probe; P1 and P2, pressure transducers; R, resistance transducer; and GC, gas chromatographer.

fuel gas. ${ }^{10-18}$ However, little is known about recovering $\mathrm{CH}_{4}$ from the $\mathrm{CH}_{4} / \mathrm{N}_{2}$ gas mixture. Happel et al. ${ }^{19}$ first proposed the different equilibrium conditions of the hydrate formation. Recently, the hydrate-based separation technology was adopted in the recovery of $\mathrm{CH}_{4}$ from the CBM resource. ${ }^{20-26}$ According to literature, the hydrate formation pressure of $\mathrm{CH}_{4}, \mathrm{~N}_{2}$, and the $\mathrm{CH}_{4} / \mathrm{N}_{2}$ gas mixture with $50.25 \mathrm{~mol} \% \mathrm{CH}_{4}$ are 5.02, 28.29, and $6.13 \mathrm{MPa}$, respectively, in the pure water system at a constant temperature (approximately $279.15 \mathrm{~K}$ ).$^{27-29}$ Hence, the $\mathrm{CH}_{4}$ hydrate can be formed more easily than the $\mathrm{N}_{2}$ hydrate by controlling the operating pressure at the constant temperature.

However, the hydrate formation rate, the amount of the gas uptake, and the $\mathrm{CH}_{4}$ separation efficiency are key factors which determine the application of the hydrate-based $\mathrm{CH}_{4}$ separation technology in industry. Furthermore, in the pure water system, the hydrate formation pressure of the $\mathrm{CH}_{4} / \mathrm{N}_{2}$ gas mixture is too high to engender huge equipment and operating costs for the application of the hydrate-based separation in industry and the hydrate formation rate is too low to achieve large scale gas separation. In order to effectually lower the hydrate formation pressure and improve hydrate formation rate, the amount of the gas uptake, and the $\mathrm{CH}_{4}$ separation efficiency, the hydrate formation additives or promoters, such as tetrahydrofuran (THF), sodium dodecyl sulfate (SDS), and tetrabutylammonium bromide (TBAB) are added in the separation processes. The formation pressure of the $\mathrm{CH}_{4}$ and $\mathrm{N}_{2}$ hydrate sharply drops in the systems with THF but the amount of the gas uptake and the $\mathrm{CH}_{4}$ separation efficiency obviously decrease as well. $^{21,22}$ However, Zhang et al. ${ }^{22}$ demonstrated that methane can be directly separated from the methane, nitrogen, and oxygen gas mixture via hydrate formation in the tetrahydrofuran solution without the pretreatments of deoxygenation. Nevertheless, the formation pressure of the $\mathrm{CH}_{4}$ and $\mathrm{N}_{2}$ hydrate is quite high in the SDS solution ${ }^{21}$ and the $\mathrm{CH}_{4}$ separation efficiency is only improved up to approximately $50 \%$ in the TBAB solution in the presence of SDS. ${ }^{23}$ Therefore, the above hydrate formation systems are not available to recover $\mathrm{CH}_{4}$ from the drainage CBM efficiently and reduce the cost in industrial application. Thus, it is necessary to study a new system to increase the hydrate formation rate, the amount of the gas uptake, and the $\mathrm{CH}_{4}$ separation efficiency.

In this work, THF and SDS are adopted as the mixture promoter. Effects of the additions of the SDS with the different concentrations in $1.0 \mathrm{~mol} \% \mathrm{THF}$ aqueous solution and the different initial operating pressures on the hydrate formation rate, the amount of the gas uptake, the $\mathrm{CH}_{4}$ concentration in the decomposed gas phase, the $\mathrm{CH}_{4}$ split fraction, and the $\mathrm{CH}_{4}$ separation factor were investigated. The purpose is to find the optimal condition for recovering $\mathrm{CH}_{4}$ from the drainage CBM.

\section{MATERIALS AND METHODS}

2.1. Apparatus. Figure 1 shows the schematic of the experimental apparatus. ${ }^{12}$ It consists of a supply vessel (SV) and a high hydrate crystallizer (CR) made of 316 stainless steel. The $\mathrm{CR}$ with an effective volume of $336 \mathrm{~mL}$ and the SV with the maximum volume of $1250 \mathrm{~mL}$ 
Table 1. Experimental Conditions along with Composition Analysis and Separation Efficiencies for Different Systems

\begin{tabular}{|c|c|c|c|c|c|c|c|c|c|c|c|c|}
\hline \multirow[b]{2}{*}{ runs } & \multirow[b]{2}{*}{ system } & \multirow[b]{2}{*}{$T(\mathrm{~K})$} & \multirow[b]{2}{*}{$\begin{array}{c}P \\
(\mathrm{MPa})\end{array}$} & \multicolumn{2}{|c|}{$\begin{array}{l}\text { concentration in } \\
\text { residual gas } \\
\text { phase }(\mathrm{mol} \%)\end{array}$} & \multicolumn{2}{|c|}{$\begin{array}{l}\text { concentration in } \\
\text { decomposed gas } \\
\text { phase (mol \%) }\end{array}$} & \multirow[b]{2}{*}{$\begin{array}{l}\text { gas uptake } \\
(\mathrm{mol})\end{array}$} & \multirow[b]{2}{*}{ S.Fr. } & \multirow[b]{2}{*}{ S.F. } & \multirow[b]{2}{*}{$\begin{array}{c}t_{i}^{a} \\
(\min )\end{array}$} & \multirow[b]{2}{*}{$\begin{array}{c}\mathrm{V}^{b} \\
(\mathrm{~mol} / \mathrm{min}) \times 10^{-3}\end{array}$} \\
\hline & & & & $\mathrm{CH}_{4}$ & $\mathrm{~N}_{2}$ & $\mathrm{CH}_{4}$ & $\mathrm{~N}_{2}$ & & & & & \\
\hline 1 & $1.0 \mathrm{~mol} \% \mathrm{THF}$ & 279.15 & 3.50 & 47.37 & 52.63 & 58.09 & 41.91 & 0.1490 & 0.7218 & 2.38 & 8.5 & 1.43 \\
\hline 2 & $\begin{array}{l}1.0 \mathrm{~mol} \% \mathrm{THF}+250 \mathrm{ppm} \\
\text { SDS }\end{array}$ & 279.15 & 3.50 & 42.10 & 57.90 & 66.40 & 33.60 & 0.1632 & 0.6183 & 3.56 & 5.2 & 1.29 \\
\hline 3 & $\underset{\mathrm{SDS}^{c}}{1.0 \mathrm{~mol}} \% \mathrm{THF}+300 \mathrm{ppm}$ & 279.15 & 3.50 & 46.06 & 53.94 & 58.78 & 44.22 & 0.1501 & 0.7757 & 2.17 & 7.2 & 1.65 \\
\hline 4 & $\begin{array}{l}1.0 \mathrm{~mol} \% \mathrm{THF}+300 \mathrm{ppm} \\
\text { SDS }\end{array}$ & 279.15 & 3.50 & 45.61 & 54.39 & 65.73 & 41.27 & 0.1682 & 0.8187 & 3.34 & 2.3 & 1.39 \\
\hline 5 & $\begin{array}{l}1.0 \mathrm{~mol} \% \mathrm{THF}+500 \mathrm{ppm} \\
\text { SDS }\end{array}$ & 279.15 & 3.50 & 45.24 & 54.76 & 65.17 & 34.83 & 0.1454 & 0.6880 & 3.79 & 1.6 & 1.97 \\
\hline 6 & $\begin{array}{l}1.0 \mathrm{~mol} \% \mathrm{THF}+1000 \mathrm{ppm} \\
\text { SDS }\end{array}$ & 279.15 & 3.50 & 41.68 & 58.32 & 71.19 & 29.81 & 0.1185 & 0.7732 & 7.49 & 1.5 & 1.14 \\
\hline 7 & $\begin{array}{l}1.0 \mathrm{~mol} \% \mathrm{THF}+300 \mathrm{ppm} \\
\text { SDS }\end{array}$ & 279.15 & 1.50 & 38.43 & 61.57 & 70.59 & 29.41 & 0.0808 & 0.9005 & 15.08 & 42 & 0.44 \\
\hline 8 & $\begin{array}{l}1.0 \mathrm{~mol} \% \mathrm{THF}+300 \mathrm{ppm} \\
\text { SDS }\end{array}$ & 279.15 & 2.50 & 39.46 & 60.54 & 69.93 & 30.07 & 0.1364 & 0.8644 & 10.77 & 9.5 & 1.11 \\
\hline 9 & $\begin{array}{l}1.0 \mathrm{~mol} \% \mathrm{THF}+300 \mathrm{ppm} \\
\text { SDS }\end{array}$ & 279.15 & 4.50 & 45.23 & 54.77 & 64.35 & 35.65 & 0.1636 & 0.6908 & 3.60 & 1.4 & 1.49 \\
\hline
\end{tabular}

are located inside the temperature-controlled water bath. The CR contains two visible windows to observe the process of hydrate formation. The contents in the $\mathrm{CR}$ are agitated by a magnetic stirrer $(0-1000 \mathrm{rpm})$. The pressure in the CR and SV is measured using a MBS3000 absolute pressure transducer $(0-25 \mathrm{MPa})$ with $\pm 0.02 \mathrm{MPa}$ accuracy. The temperature in the $\mathrm{CR}$ is measured using a Pt1000 thermo probe (JM6081) with the uncertainty of $\pm 0.1 \mathrm{~K}$. The signals of the pressure and temperature are acquired by a data acquisition system driven by a personal computer (PC). Hydrate formation experiments are conducted in a semibatch manner at constant pressure and temperature. The gas from the SV is supplied continuously into the $\mathrm{CR}$ to ensure the constant pressure of the $\mathrm{CR}$.

2.2. Materials. The $\mathrm{CH}_{4}$ and $\mathrm{N}_{2}$ mixture gas with $50 \mathrm{~mol} \% \mathrm{CH}_{4}$ supplied by Guangdong South China Special Gases Technology Institute Ltd., China, was used to model the drainage CBM. THF with a purity of $99.9 \%$ was supplied by Tianjin Kermel Chemical Reagent Co., Ltd., China. SDS with a purity of $99.9 \%$ was supplied by Tianjin Fuchen Chemical Reagent Co., Ltd. The deionized water was obtained by an ultrapure water system with a resistivity of $18.25 \mathrm{~m} \Omega \cdot \mathrm{cm}^{-1}$ made by Nanjing Ultrapure Water Technology Co., Ltd., China. GC522 gas chromatography (GC) was supplied by Shanghai Wu Feng Scientific instrument Co., Ltd.

2.3. Procedures. In this work, all hydrate formation experiments are carried out in a semibatch manner with $180 \mathrm{~mL}$ volume of solution and a continuous supply of gas at constant pressure and temperature. The experimental procedure of hydrate formation and separation experiment is similar to that of recovering $\mathrm{CO}_{2}$ from flue or fuel gas. ${ }^{12}$ In the experiments, the $1.0 \mathrm{~mol} \%$ THF solutions with different mass concentration of SDS (0, 250,300, 500, $1000 \mathrm{ppm})$ are used. (1) Before doing the experiment, the $\mathrm{CR}$ is cleaned using deionized water and dried. Then, the $180 \mathrm{~mL}$ solution prepared with a desired concentration is introduced into the $\mathrm{CR}$ for each experiment. Subsequently, the CR with the solution is flushed with the $\mathrm{CH}_{4} / \mathrm{N}_{2}$ gas mixture at least four times to ensure that is air-free, and then the $\mathrm{CH}_{4} / \mathrm{N}_{2}$ gas mixture is charged into the cell for the desired initial operating pressure. (2) Once the temperature is stabilized, the magnetic stirrer in the CR is started at the speed of $500 \mathrm{rpm}$ and the experimental time also begins to be recorded as 0 . As the gas in the $\mathrm{CR}$ is consumed on account of the hydrate formation, high pressure gas automatically flows from the SV into the CR to maintain the constant operating pressure through the proportional-integral-derivative (PID) control system. During the experiment, the temperature and pressure in the system are recorded by a PC automatically. (3) After the system pressure is maintained constant for more than half an hour, the hydrate formation is considered to be completed. The magnetic stirrer is stopped, and the residual gas is sampled and analyzed with GC. Moreover, the change of moles of gas consumption in the CR (gas uptake) with time $(t)$ can be calculated by the equation given by Linga et al. ${ }^{18}$ The moles of the gas uptake $\left(\Delta n_{\mathrm{H}}\right)$ can be expressed as follows:

$$
\begin{aligned}
\Delta n_{\mathrm{H}} & =n_{\mathrm{H}, 0}-n_{\mathrm{H}, t} \\
& =\left(\frac{P V}{z R T}\right)_{\mathrm{G}, 0}-\left(\frac{P V}{z R T}\right)_{\mathrm{G}, t}+\left(\frac{P V}{z R T}\right)_{\mathrm{SV}, 0}-\left(\frac{P V}{z R T}\right)_{\mathrm{SV}, t}
\end{aligned}
$$

where $z$ is the compressibility factor calculated by Pitzer's correlation. ${ }^{30}$ The subscript $t$ refers to time $t$. The subscript 0 refers to the initial time. The subscript $G$ refers to the gas phase in the crystallizer. The subscript SV refers to the gas phase in the supply vessel. (4) After the end of hydrate formation, the pressure in the CR is quickly depressurized to atmospheric pressure, and then, it is closed. Thus, the hydrate is allowed to dissociate completely by heating to 293.15 K. Subsequently, the gas, which evolved from the decomposed hydrate and was released from the solution, is collected in the CR, and the composition of the decomposed gas phase is determined by GC.

Prior to commencing the separation experiment, one cycle of hydrate formation and decomposition is carried out to ensure the memory effect. The solution with the memory effect can obviously shorten the induction time of the hydrate formation. ${ }^{31}$

2.4. $\mathrm{CH}_{4}$ Separation Efficiency. The separation efficiency can be determined by the $\mathrm{CH}_{4}$ recovery or split fraction (S.Fr.) and $\mathrm{CH}_{4}$ separation factor (S.F.), which can be obtained according to the following equations. ${ }^{17,32}$

$$
\begin{gathered}
\text { S.Fr. }=\frac{n_{\mathrm{CH}}^{\mathrm{H}}}{n_{\mathrm{CH}}^{\mathrm{feed}}} \\
\text { S.F. }=\frac{n_{\mathrm{CH}_{4}}^{\mathrm{H}}{ }^{n}{ }_{\mathrm{N}_{2}}^{\mathrm{G}}}{n_{\mathrm{N}_{2}}^{\mathrm{H}}{ }_{\mathrm{CH}}^{\mathrm{G}}}
\end{gathered}
$$

where $n_{\mathrm{CH}_{4}}^{\text {feed }}$ is defined as the moles of $\mathrm{CH}_{4}$ in the feed gas. $n_{\mathrm{CH}_{4}}^{\mathrm{H}}$ and $n_{\mathrm{CH}_{4}}^{\mathrm{G}}$ are the moles of $\mathrm{CH}_{4}$ in the hydrate and gas phases, respectively. $n_{\mathrm{N}_{2}}^{\mathrm{H}}$ and $n_{\mathrm{N}_{2}}^{\mathrm{G}}$ are the moles of $\mathrm{N}_{2}$ in the hydrate and gas phases, respectively. 


\section{RESULTS AND DISCUSSION}

In this work, a total of nine experimental runs were carried out to investigate the $\mathrm{CH}_{4}$ separation efficiencies of hydrate formation at the different conditions, including the fresh and memory water (runs 3 and 4), the different SDS concentrations in the $1.0 \mathrm{~mol} \% \mathrm{THF}$ aqueous solution (runs 1, 2, 4, 5, and 6) and the different initial operating pressure (runs 4, 7, 8, and 9), to find the optimal operating conditions for recovering and concentrating $\mathrm{CH}_{4}$ from the drainage $\mathrm{CBM}$ via hydrate formation. Table 1 summarizes the results from the separation experiments with the different conditions.

3.1. Memory Effect. Memory refers to the situation where water that is used in the experiments has experienced hydrate formation. ${ }^{33}$ As a typical case, Figure 2 gives the moles of gas

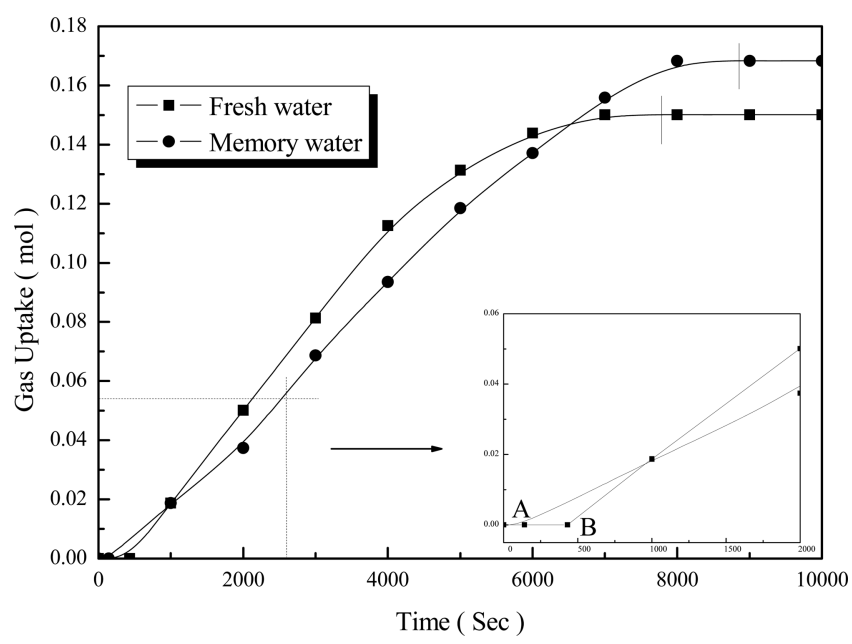

Figure 2. Gas uptake curves for $1.0 \mathrm{~mol} \%$ THF aqueous solution in the presence of $300 \mathrm{ppm}$ SDS with fresh and the memory water at $279.15 \mathrm{~K}$ and $3.50 \mathrm{MPa}$ for runs 3 and 4.

consumed (amount of gas uptake) for hydrate formation in the presence of the $300 \mathrm{ppm}$ SDS in the $1.0 \mathrm{~mol} \%$ THF aqueous solution with fresh and memory water at $279.15 \mathrm{~K}$ and 3.50 $\mathrm{MPa}$ for runs 3 and 4 . It can be seen from Figure 2 that the time corresponding to point $\mathrm{A}$ is the induction time in the memory water and that corresponding to point $B$ is the induction time in the fresh water. The explanation for this can be given elsewhere. ${ }^{14}$ As shown in Figure 2, the induction time in the memory water $(2.3 \mathrm{~min})$ is approximately a third as long as that in the fresh water $(7.2 \mathrm{~min})$ due to the memory effect. It can also be seen from Figure 2 that the moles of gas uptake with the fresh and memory water increase gradually in the processes of the hydrate formation and reach the plateau after approximately 2.0 and $2.5 \mathrm{~h}$, respectively. It may be due to the fact that the gas hydrate forms substantially and agglomerates at the gas/liquid interface as the experiments progress. Extensive hydrate formation and crystal agglomeration result in the accumulation of crystals as stagnant pockets at the gas/water interface which prevents more gas from coming into contact with the water. The similar phenomenon can be found elsewhere. ${ }^{31}$ In addition, it is also shown in Figure 2 that the final amount of the gas uptake obtained from the memory water $(0.1682 \mathrm{~mol})$ is approximately $12 \%$ higher than that obtained from the fresh water $(0.1501 \mathrm{~mol})$. Figure 3 gives the $\mathrm{CH}_{4}$ concentration in decomposed gas phase, the $\mathrm{CH}_{4}$ split fraction, and the $\mathrm{CH}_{4}$ separation factor for $1.0 \mathrm{~mol} \% \mathrm{THF}$ aqueous solution in the presence of $300 \mathrm{ppm}$ SDS with the

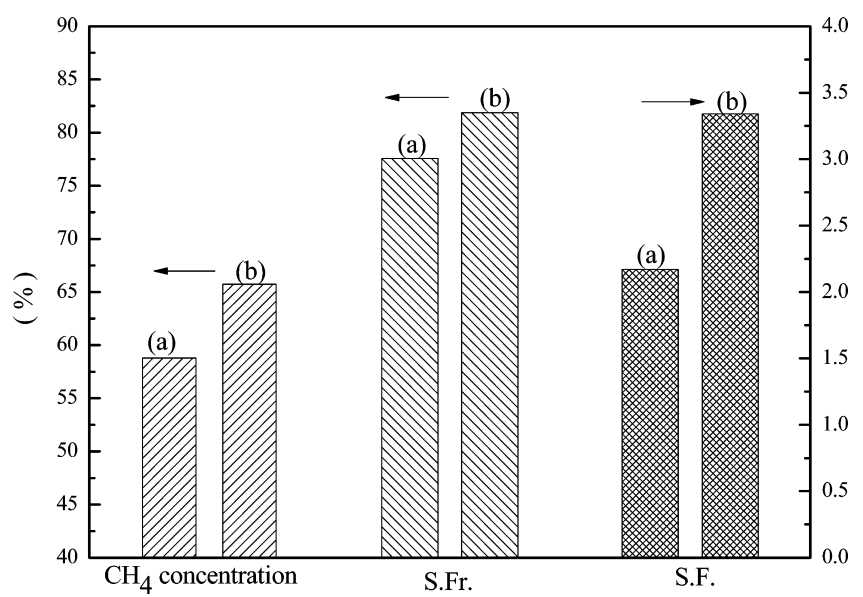

Figure 3. $\mathrm{CH}_{4}$ concentration in decomposed gas phase, $\mathrm{CH}_{4}$ split fraction (S.Fr.), and $\mathrm{CH}_{4}$ separation factor (S.F.) for $1.0 \mathrm{~mol} \% \mathrm{THF}$ aqueous solution in the presence of $300 \mathrm{ppm}$ SDS with the fresh water (a) and memory water (b) at $279.15 \mathrm{~K}$ and $3.50 \mathrm{MPa}$.

fresh water and memory water at $279.15 \mathrm{~K}$ and $3.50 \mathrm{MPa}$. As shown in Figure 3, the $\mathrm{CH}_{4}$ concentration in the decomposed gas phase, the $\mathrm{CH}_{4}$ split fraction, and the $\mathrm{CH}_{4}$ separation factor with the memory water, approximately $65 \mathrm{~mol} \%, 82 \%$, and 3.34 , are higher than those with the fresh water, approximately $58 \mathrm{~mol} \%, 78 \%$, and 2.17 , respectively. Hence, the memory water is more abstractive and effective for the $\mathrm{CH}_{4}$ recovery from the $\mathrm{CH}_{4} / \mathrm{N}_{2}$ gas mixture in the application in industry. Actually, using the memory water circularly to recover $\mathrm{CH}_{4}$ from the drainage CBM meets also the requirement of the operational process in industry. Thus, the following experiments are carried out in the memory water.

3.2. Effect of SDS Concentration. Figure 4 shows the change of gas uptakes for hydrate formation in the $1.0 \mathrm{~mol} \%$

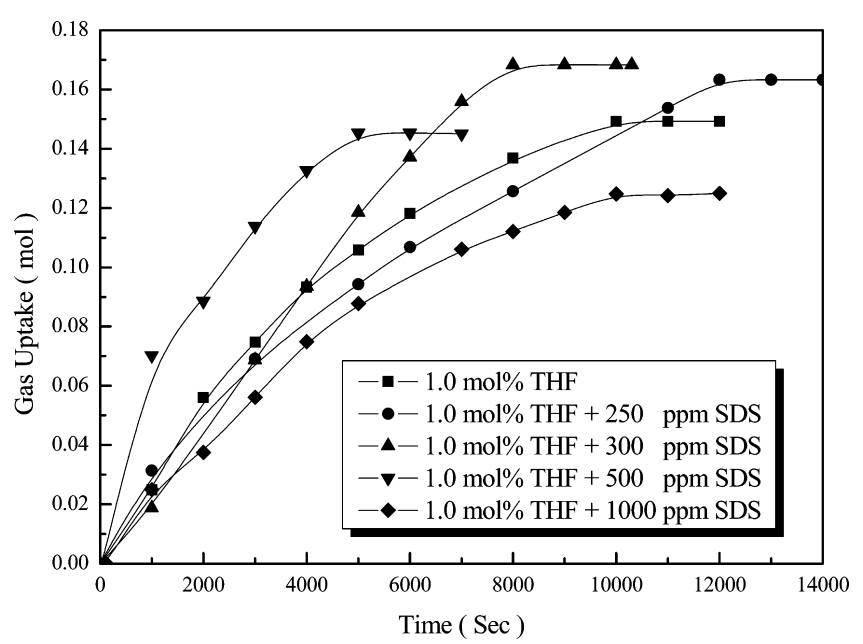

Figure 4. Gas uptake measurements for five experiments conducted at $3.50 \mathrm{MPa}$ and $279.15 \mathrm{~K}$ in the systems with different SDS concentrations $(0,250,300,500,1000 \mathrm{ppm})$ for runs $1,2,4,5$, and 6 .

THF aqueous solutions in the presence of SDS with the different concentrations at $279.15 \mathrm{~K}$ and $3.50 \mathrm{MPa}$ for runs 1 , $2,4,5$, and 6 . As seen, the hydrate formation rate in the initial stage of the hydrate formation process is high and, then, reduces gradually. Eventually, the hydrate formation rate for runs $1,2,4,5$, and 6 has little change after approximately 3.1, 


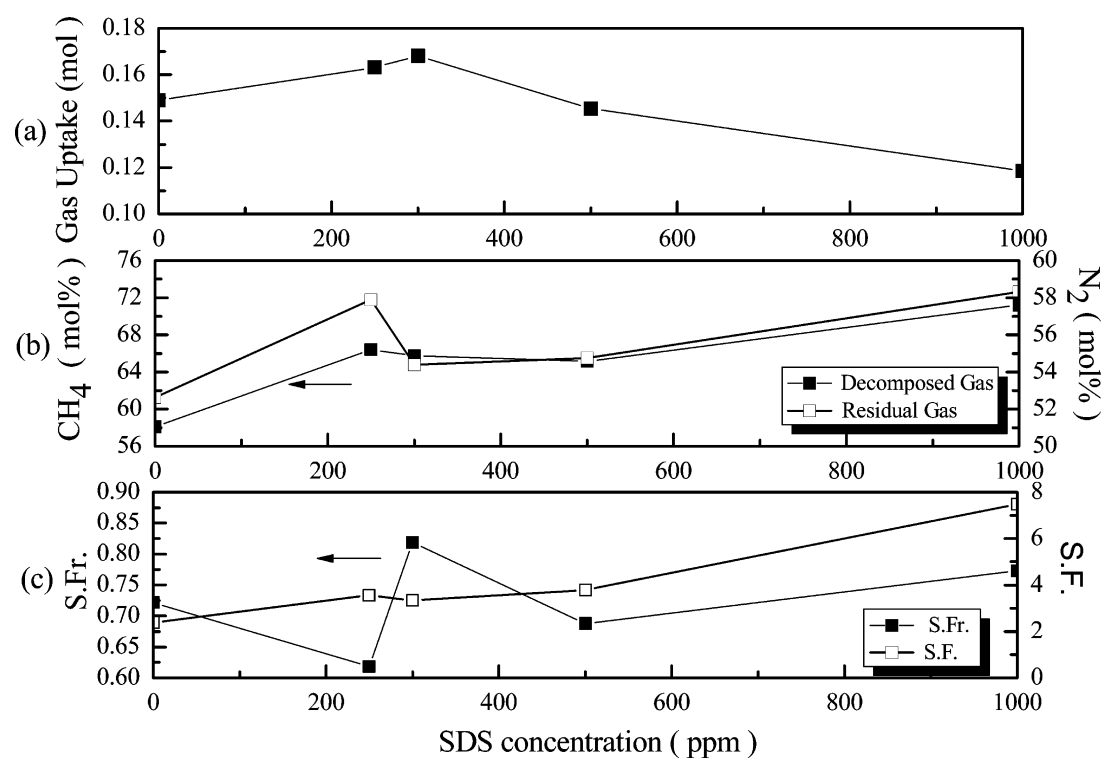

Figure 5. Hydrate formation from systems with $1.0 \mathrm{~mol} \%$ THF solution in the presence of $0-1000 \mathrm{ppm}$ SDS at $279.15 \mathrm{~K}$ and $3.50 \mathrm{MPa}$ (a) the gas uptake, (b) $\mathrm{N}_{2}$ concentration in residual gas, and $\mathrm{CH}_{4}$ concentration in decomposed gas phase and (c) $\mathrm{CH}_{4}$ split fraction (S.Fr.) and $\mathrm{CH}_{4}$ separation factor (S.F.).

3.6, 2.2, 1.7, and $3.0 \mathrm{~h}$, respectively. The reason for this is explained in Figure 2. In addition, from Figures 4 and 5a, it can be found that the maximum of the gas uptake $(0.1682 \mathrm{~mol})$ can be obtained in the system with $300 \mathrm{ppm}$ SDS and the minimum $(0.1185 \mathrm{~mol})$ can be obtained in the system with $1000 \mathrm{ppm}$ SDS.

It is noted that the final amount of gas uptake presents an increasing trend for the systems with SDS concentration from 0 to $300 \mathrm{ppm}$. However, the final amount of gas uptake reduces with the increase of SDS concentration from 300 to $1000 \mathrm{ppm}$. As seen from Table 1 and Figure 5a, the final amount of the gas uptake in the system with $250 \mathrm{ppm}$ SDS is $0.1632 \mathrm{~mol}$ and it is enhanced $9.5 \%$ relative to the system without SDS $(0.1490$ $\mathrm{mol}$ ). The final amount of the gas uptake in the system with $300 \mathrm{ppm}$ SDS is up to $0.1682 \mathrm{~mol}$, which is $12.9 \%$ higher than that in the system without SDS. In addition, it is found that the final amount of the gas uptake in the system with $1000 \mathrm{ppm}$ SDS is $0.1185 \mathrm{~mol}$, and it is decreased by approximately $21 \%$ relative to that in the system without SDS. The differences of the gas uptakes in the systems with various SDS concentrations are because of the characteristics of SDS as a surfactant in the solution. We fitted the critical micelle concentration (CMC) data of SDS at different temperatures given by the literature ${ }^{34-37}$ and determined that the CMC of SDS at $279.15 \mathrm{~K}$ is approximately $350 \mathrm{ppm}$ in the work. Thus, the SDS concentration of $300 \mathrm{ppm}$ is slightly lower than its CMC and that of $500 \mathrm{ppm}$ is higher than its CMC. When the SDS concentration is lower than CMC, with the increase of the SDS concentration, $\mathrm{DS}^{-}$monomers in the solution gradually accumulate on the gas/liquid surface, gradually form the DS monomolecular film, and, thus, cause the gradual decrease of the surface energy, i.e., the gradual decrease of the surface tension. When the SDS concentration is equal to the CMC, the $\mathrm{DS}^{-}$monomolecular film is saturated by $\mathrm{DS}^{-}$monomers. At the time, the surface tension is lowest. When the SDS concentration is higher than $\mathrm{CMC}$, the $\mathrm{DS}^{-}$monomers exist in the solution in the form of the micelles. During the period, the system surface tension remains the lowest value and has no change. Therefore, the surface tension in the system with the
SDS concentration of $300 \mathrm{ppm}$ is smaller than that in the system with the SDS concentration of $250 \mathrm{ppm}$. Consequently, the lower surface tension, which means lower surface energy, leads to the gas dissolving in the solution more easily. Hence, the final amount of gas uptake in the system with 300 ppm SDS is higher than that in the system with $250 \mathrm{ppm}$ SDS. However, when the SDS concentration is higher than its CMC, with the increase of the $\mathrm{DS}^{-}$micelles, more crystal nucleuses for hydrate formation are bundled in the hydrophobic domains formed by adsorbed $\mathrm{DS}^{-}$monomers and the contact of gas and hydrate crystal nucleuses is frustrated to form more hydrates. ${ }^{31}$ Thus, the gas uptake reduces as the SDS concentration increases from 500 to $1000 \mathrm{ppm}$.

In addition, as shown in Figure 5b, the $\mathrm{CH}_{4}$ concentrations in the decomposed gas phase obtained from the systems with SDS are higher than that obtained from the system without SDS (approximately $58 \mathrm{~mol} \%$ ). This indicates that $\mathrm{DS}^{-}$ monomers are favorable for forming the $\mathrm{CH}_{4}$ hydrate preferentially in THF solutions. This may be attributed to the existence of the $\mathrm{DS}^{-}$monomolecular film and the abundant SDS micelles in solutions, which make the $\mathrm{CH}_{4}$ molecules go into the solution more easily than the $\mathrm{N}_{2}$ molecules because $\mathrm{CH}_{4}$ and $\mathrm{DS}^{-}$have similar alkyl radical structures. Also, it can be seen from Figure $5 b$ that the $\mathrm{CH}_{4}$ concentration in the decomposed gas phase at the SDS concentration of $250 \mathrm{ppm}$ (less than CMC) is slightly higher than that at the SDS concentrations of $300 \mathrm{ppm}$ (close to $\mathrm{CMC}$ ) and has little change in the SDS concentration range from 300 to $500 \mathrm{ppm}$. Subsequently, the $\mathrm{CH}_{4}$ concentration has a relatively large increase with the SDS concentration changes from 500 to 1000 ppm. The reason is not very clear. This requires our further research in the future work. The $\mathrm{N}_{2}$ concentration in the residual gas phase has the similar change trend with the $\mathrm{CH}_{4}$ concentration in decomposed gas phase as the SDS concentration increases from 0 to $1000 \mathrm{ppm}$.

The $\mathrm{CH}_{4}$ separation factor indicates the separation ability of recovering $\mathrm{CH}_{4}$ from the $\mathrm{CH}_{4} / \mathrm{N}_{2}$ gas mixture. Figure $5 \mathrm{c}$ shows the changes of the $\mathrm{CH}_{4}$ separation factor with the increase of SDS concentration at $279.15 \mathrm{~K}$ and $3.50 \mathrm{MPa}$ after one-stage 
hydrate-based separation. Moreover, it has a similar change trend with the $\mathrm{CH}_{4}$ concentrations in the decomposed gas phase with the increase of SDS concentration. Thus, the experimental results indicate that the $\mathrm{CH}_{4}$ separation factors in the systems with SDS are higher than that in the system without SDS (approximately 2.4). This proves that SDS has a positive influence on the recovery of $\mathrm{CH}_{4}$ from the $\mathrm{CH}_{4} / \mathrm{N}_{2}$ gas mixture via hydrate formation. It can be seen in Figure $5 \mathrm{c}$ that the $\mathrm{CH}_{4}$ separation factor only changes by approximately 0.2 with the increase of SDS concentration from 250 to $500 \mathrm{ppm}$. However, when the SDS concentration is $1000 \mathrm{ppm}$, the $\mathrm{CH}_{4}$ separation factor is twice as high (up to approximately 7.5) than that in the SDS concentration range of $250-500 \mathrm{ppm}$. This possibly results from the existence of the abundant SDS micelles in systems with $1000 \mathrm{ppm}$ SDS. Thus, the addition of SDS is also helpful to enhance the $\mathrm{CH}_{4}$ recovery ability from the $\mathrm{CH}_{4} / \mathrm{N}_{2}$ gas mixture with the hydrate-based separation technology.

Generally, the $\mathrm{CH}_{4}$ split fraction is another significant parameter in the industrial application. A separation process with a higher $\mathrm{CH}_{4}$ split fraction value can produce more products. Consequently, a bigger economic benefit can be obtained. Figure $5 \mathrm{c}$ also gives the change of the $\mathrm{CH}_{4}$ split fraction vs the SDS concentration at $279.15 \mathrm{~K}$ and $3.50 \mathrm{MPa}$ after one-stage hydrate-based separation. The experimental results indicate that the maximum of the $\mathrm{CH}_{4}$ split fraction $(81.87 \%)$ obtained in the system with $300 \mathrm{ppm}$ SDS is approximately $10 \%$ higher than that obtained in the system without SDS (72.18\%). Furthermore, the minimum of the $\mathrm{CH}_{4}$ split fraction $(61.82 \%)$ is obtained in the system with $250 \mathrm{ppm}$ SDS. It illustrates that the maximum of the $\mathrm{CH}_{4}$ split fraction can be obtained when the SDS concentration is near its CMC value.

Thus, as seen from Figures 4 and 5, the experimental results indicate that the system with SDS can effectively recover $\mathrm{CH}_{4}$ from the $\mathrm{CH}_{4} / \mathrm{N}_{2}$ gas mixture via hydrate formation. Hence, it is determined that the system with $300 \mathrm{ppm}$ SDS in $1.0 \mathrm{~mol} \%$ THF aqueous solution is the optimal system to recover $\mathrm{CH}_{4}$ from the $\mathrm{CH}_{4} / \mathrm{N}_{2}$ gas mixture via hydrate formation by considering comprehensively the $\mathrm{CH}_{4}$ separation factor and the $\mathrm{CH}_{4}$ split fraction along with the hydrate formation rate, the amount of the gas uptake, and the $\mathrm{CH}_{4}$ concentration in the decomposed gas phase. Thus, the following experiments are carried out in the $1.0 \mathrm{~mol} \% \mathrm{THF}$ aqueous solution in the presence of $300 \mathrm{ppm}$ SDS.

3.3. Effect of Initial Operating Pressure. The influences of the different initial operating pressures $(1.50,2.50,3.50$, and 4.50 MPa) on the gas uptakes, the $\mathrm{CH}_{4}$ concentrations in decomposed gas phases, the $\mathrm{CH}_{4}$ split fractions, and the $\mathrm{CH}_{4}$ separation factors are investigated in the system with $300 \mathrm{ppm}$ SDS at $279.15 \mathrm{~K}$ for runs 4, 7, 8, and 9. As shown in Figure 6, the amount of the gas uptake increases with the increase of the initial operating pressure from 1.50 to $3.50 \mathrm{MPa}$. It may be attributed to the fact, on the one hand, that the higher initial operating pressure makes more gas go into the THF aqueous solution and furthermore causes more gas hydrate to form, resulting in more gas consumed; on the other hand, the increase of the amount of gas going into the solution correlates with the enhancement of the gas hydrate growth rate, which also means the enhancement of the gas consumption rate. However, the amount of gas uptake at $4.50 \mathrm{MPa}$ is slightly smaller than that at $3.50 \mathrm{MPa}$. This may be due to the fact that the gas hydrate forms substantially and agglomerates at the gas/

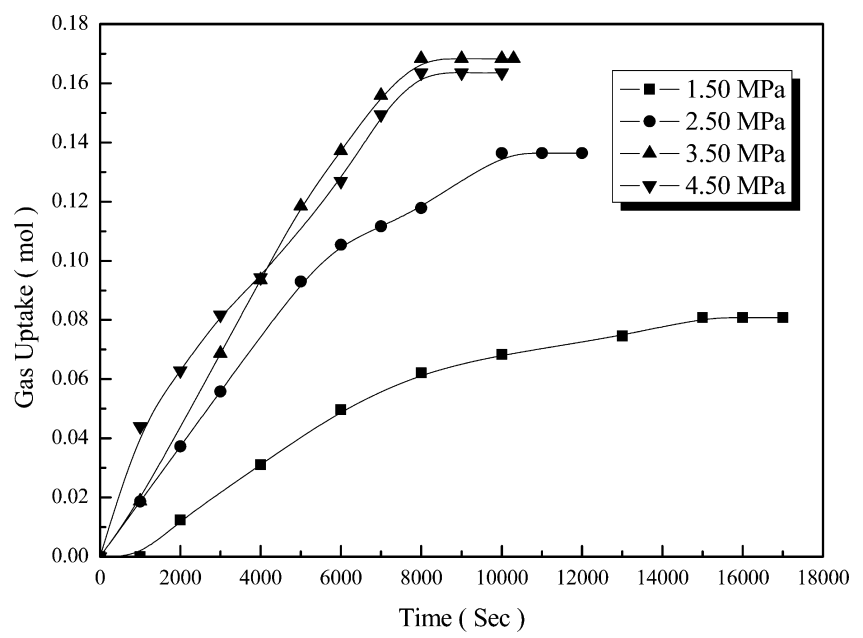

Figure 6. Gas uptake measurements for four experiments conducted at $279.15 \mathrm{~K}$ and different initial operating pressures $(1.50,2.50,3.50$, and 4.50 MPa) in the systems with $1.0 \mathrm{~mol} \%$ THF solution in the presence of $300 \mathrm{ppm}$ SDS for runs 4, 7, 8, and 9 .

liquid interface when the initial operating pressure is relatively high. Extensive hydrate formation and crystal agglomeration results in the accumulation of crystals as stagnant pockets at the gas/water interface which prevents more gas from coming into contact with the water. Thus, more agglomeration results in a smaller amount of gas in the solution for hydrate formation. It can be seen in Figure 7a that the maximum amount of gas uptake at $3.50 \mathrm{MPa}$ is $0.1682 \mathrm{~mol}$, which is slightly higher than the final amount of gas uptake at $4.50 \mathrm{MPa}(0.1636 \mathrm{~mol})$. In addition, the final amount of gas uptake at $3.50 \mathrm{MPa}$ is twice that at $1.50 \mathrm{MPa}(0.0808 \mathrm{~mol})$.

It can be seen from Figure 6 that the hydrate formation rates slow down and reach the individual plateau after approximately $4.56,3.19,2.22$, and $2.20 \mathrm{~h}$ at $1.50,2.50,3.50$, and $4.50 \mathrm{MPa}$, respectively. Similar behaviors were observed for runs 1-6. Generally, the hydrate formation rates at 3.50 and $4.50 \mathrm{MPa}$ are higher than those at 1.50 and $2.50 \mathrm{MPa}$. In addition, the reaction time at 3.50 and $4.50 \mathrm{MPa}$ shortens by approximately $2 \mathrm{~h}$, compared with that at $1.50 \mathrm{MPa}$.

Figure $7 \mathrm{~b}$ shows the changes of the $\mathrm{N}_{2}$ concentration in the residual gas phase and the $\mathrm{CH}_{4}$ concentration in the decomposed gas phase at the initial operating pressure range from 1.50 to $4.50 \mathrm{MPa}$ in $1.0 \mathrm{~mol} \% \mathrm{THF}$ aqueous solution in the presence of 300 SDS after one-stage hydrate-based separation at $279.15 \mathrm{~K}$. As seen, they all decrease with the increase of the initial operating pressure. It is noted that the higher initial operating pressure can not entrap more of the $\mathrm{CH}_{4}$ molecules in the hydrate slurry phase. As seen in Figure $7 \mathrm{~b}$, the $\mathrm{N}_{2}$ concentrations in the residual gas phase decrease from $61.57 \mathrm{~mol} \%$ at $1.50 \mathrm{MPa}$ to $54.39 \mathrm{~mol} \%$ at $3.50 \mathrm{MPa}$ and the $\mathrm{CH}_{4}$ concentrations in the decomposed gas phase decrease from $70.59 \mathrm{~mol} \%$ at $1.50 \mathrm{MPa}$ to $64.35 \mathrm{~mol} \%$ at $4.50 \mathrm{MPa}$. Moreover, as shown in Figure $7 \mathrm{c}$, the $\mathrm{CH}_{4}$ split fraction shows a similar reduction trend with the increase of initial operating pressure and achieves the biggest value of approximately $90 \%$ when the initial operating pressure is $1.50 \mathrm{MPa}$. In fact, the above change characteristics can be explained by the different selectivity of $\mathrm{CH}_{4}$ and $\mathrm{N}_{2}$ in the hydrate formation process with the different initial operating pressures. In comparison to the $\mathrm{N}_{2}$ molecules, the $\mathrm{CH}_{4}$ molecules are preferential to form the $\mathrm{CH}_{4}$ hydrate at a lower initial operating pressure; however, the 


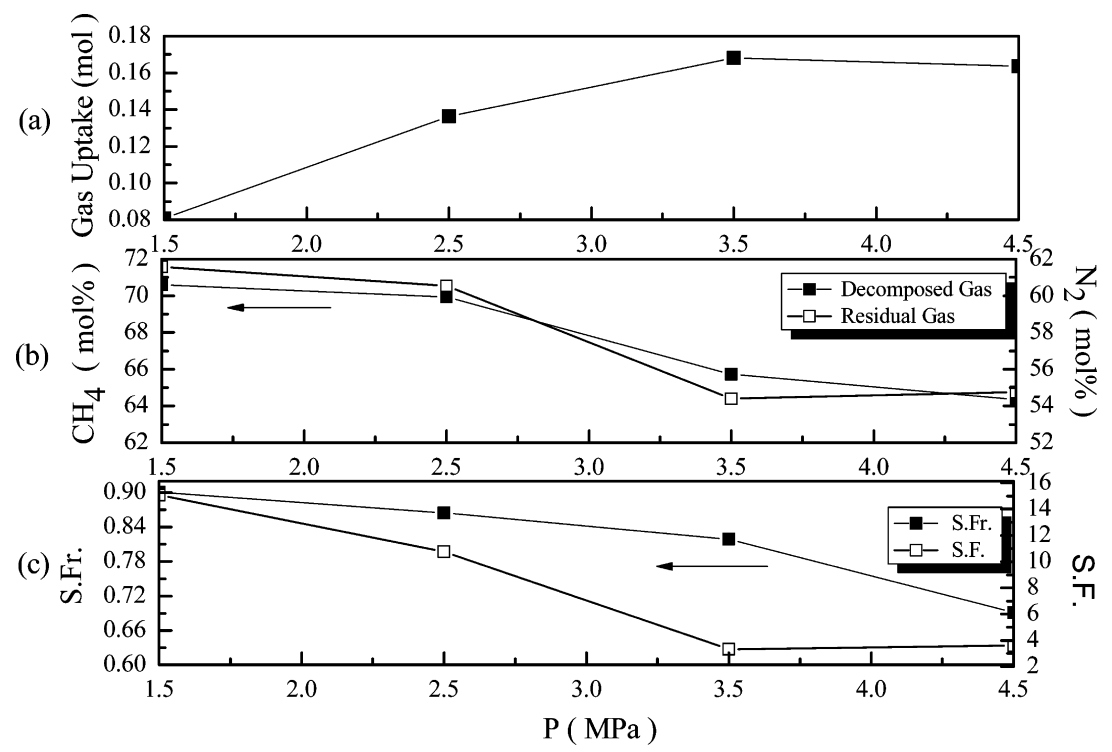

Figure 7. Hydrate formations from systems with $1.0 \mathrm{~mol} \% \mathrm{THF}$ in the presence of $300 \mathrm{ppm}$ SDS at $279.15 \mathrm{~K}$ and different initial operating pressures: (a) the gas uptake, (b) $\mathrm{N}_{2}$ concentration in the residual gas and $\mathrm{CH}_{4}$ concentration in the decomposed gas phase, and (c) $\mathrm{CH}_{4}$ split fraction (S.Fr.) and $\mathrm{CH}_{4}$ separation factor (S.F.).

$\mathrm{N}_{2}$ molecules can begin to compete with the $\mathrm{CH}_{4}$ molecules for hydrate cage $\left(5^{12}\right)$ occupancy with a higher initial operating pressure, resulting in the decrease of the $\mathrm{CH}_{4}$ concentration in the decomposed gas phase, and the $\mathrm{CH}_{4}$ split fraction decreases with increasing the initial operating pressure.

As shown in Figure $7 \mathrm{c}$, the $\mathrm{CH}_{4}$ separation factor decreases from 15.08 to 3.44 with the increase of the initial operating pressure from 1.50 to $3.50 \mathrm{MPa}$, and it is 10.77 when the initial operating pressure is $2.50 \mathrm{MPa}$. However, it is 3.60 when the initial operating pressure is $4.50 \mathrm{MPa}$. This illustrates that the low initial operating pressure at 1.50 and $2.50 \mathrm{MPa}$ have better separation ability for recovering $\mathrm{CH}_{4}$ from $\mathrm{CH}_{4} / \mathrm{N}_{2}$ gas mixture than that at 3.50 and $4.50 \mathrm{MPa}$. Hence, it is unfavorable for recovering $\mathrm{CH}_{4}$ from $\mathrm{CH}_{4} / \mathrm{N}_{2}$ gas mixture with the high initial operating pressures.

Generally, it can be seen from the above analysis, the lower initial operating pressure can result in the higher $\mathrm{N}_{2}$ concentration in residual gas phase, $\mathrm{CH}_{4}$ concentration in decomposed gas phase, the $\mathrm{CH}_{4}$ separation factor, and $\mathrm{CH}_{4}$ split fraction. However, it can be seen from Figures 6 and $7 \mathrm{a}$ that the hydrate formation rate and the final amount of the gas uptake at $1.50 \mathrm{MPa}$ are too low to be feasible in industry. Therefore, it is necessary to determine an appropriate initial operating pressure for the separation process. It can be found from Figure 7 that the values of the $\mathrm{N}_{2}$ concentration in the residual gas phase, the $\mathrm{CH}_{4}$ concentration in the decomposed gas phase, the $\mathrm{CH}_{4}$ split fraction, and the $\mathrm{CH}_{4}$ separation factor at $2.50 \mathrm{MPa}$ are $60.54 \mathrm{~mol} \%, 69.93 \mathrm{~mol} \%, 86.44 \%$, and 10.77 , respectively. They are slightly less than those at $1.50 \mathrm{MPa}$, which are $61.57 \mathrm{~mol} \%, 70.59 \mathrm{~mol} \%, 90.05 \%$, and 15.08 , respectively. Hence, it is determined that the initial operating pressure of $2.50 \mathrm{MPa}$ is the optimal condition for recovering $\mathrm{CH}_{4}$ from the $\mathrm{CH}_{4} / \mathrm{N}_{2}$ gas mixture in the system in the presence of $300 \mathrm{ppm}$ SDS in the $1.0 \mathrm{~mol} \%$ THF aqueous solution by considering comprehensively the amount of the gas uptake, the hydrate formation rate, the $\mathrm{CH}_{4}$ concentration in the decomposed gas phase, the $\mathrm{N}_{2}$ concentration in the residual gas phase, and the $\mathrm{CH}_{4}$ split fraction and separation factor.

\section{CONCLUSIONS}

In this work, the optimal operating condition and the corresponding $\mathrm{CH}_{4}$ separation efficiency for recovering $\mathrm{CH}_{4}$ from the $\mathrm{CH}_{4} / \mathrm{N}_{2}$ gas mixture via hydrate formation were investigated in the $1.0 \mathrm{~mol} \% \mathrm{THF}$ aqueous solution at 279.15 $\mathrm{K}$. It is found that the memory water has an advantage to recover $\mathrm{CH}_{4}$ from the $\mathrm{CH}_{4} / \mathrm{N}_{2}$ gas mixture. The system with the SDS concentration nearby $\mathrm{CMC}$ and the operating conditions with low initial operating pressure are helpful to recover $\mathrm{CH}_{4}$ and can enhance the separation efficiency. However, the amount of the gas uptake is low in the system with SDS concentration above $300 \mathrm{ppm}$ or at $1.50 \mathrm{MPa}$. Thus, the $1.0 \mathrm{~mol} \%$ THF aqueous solution in the presence of 300 ppm SDS with the initial operating pressure of $2.50 \mathrm{MPa}$ is the optimal for the $\mathrm{CH}_{4}$ separation purpose. Under these conditions, the final amount of gas uptake, the $\mathrm{CH}_{4}$ concentration in the decomposed gas phase, and the $\mathrm{CH}_{4}$ split fraction and separation factor after the one-stage hydratebased process are $0.1364 \mathrm{~mol}, 69.93 \mathrm{~mol} \%, 86.44 \%$, and 10.77 , respectively. Thus, the data illustrate the conceptual process that $\mathrm{CH}_{4}$ in drainage $\mathrm{CBM}$ can be recovered efficiently via hydrate-based separating technology at mild conditions in industry.

\section{AUTHOR INFORMATION}

\section{Corresponding Author}

*Telephone: +86-20-87057037. Fax: +86-20-87034664. E-mail: lixs@ms.giec.ac.cn.

\section{Notes}

The authors declare no competing financial interest.

\section{ACKNOWLEDGMENTS}

The authors gratefully appreciate financial support from the National Natural Science Foundation of China (50874098 and 51076155) and Science \& Technology Program of Guangdong Province (2009B050600006). 


\section{REFERENCES}

(1) Petroleum. Feasibility study of coal bed methane production in China, A technology report for the EU-China Energy and Environment Programme funded by the European Union and the National Development and Reform Commission of China (EuropeA/120723/ D/SV/CN). 2008.

(2) Tang, P. C.; Yang, S. Y.; et al. The accurnulation mechanismic research of coal-bed methane reservoir. Chin. Min. Mag. 2009, 18 (2), 94-97.

(3) Shi, H. N.; Mei, Y. G.; et al. Research an application of intelligent recovery technology for Fanzhuang high rank CBM wells. Oil Drilling Prod. Technol. 2010, 32 (4), 107-111.

(4) Chen, Y. P.; Wang, Y. B.; et al. Optimization of casing program san its application to CBM pinnate horizontal well. Oil Drilling Prod. Technol. 2010, 32 (4), 81-85.

(5) Liang, W. G.; W., D.; Zhao, Y. S. Experimengtal study of coalbeds methane replacement by carbon dioxide. Chin. J. Rock Mechan. Eng. 2010, 29 (4), 665-673.

(6) Xu, C. H.; Z., G.; Long, S. X.; et al. The new technology analysis of improving the coalbed methane recovery. Explor. Tech. 2009, 5172, DOI: $10.3969 /$ j.issn.1672-7703.

(7) Pilcher, R. C.; C. M., M.; Collings, R. C.;et al. Recent trends in recovery \& use of coal mine methane. The 3rd international conference of pollution-reducing technology of methane and nitrous oxide, Bejing, Nov. 6-7, 2003; pp 5-122.

(8) Kerr, T.; Yang, M. Coal mine methane in China: A budding asset with the potential to bloom, An assessment of technology, policy and financial issues relating to CMM in China, based on interviews conduced at coal mines in Guizhou and Sichuan Provinces, International Energy Agency, 2009.

(9) Guo, P.; L., M. Research progress of separation of $\mathrm{CH}_{4} / \mathrm{N}_{2}$ in coal-bed methane. Chem. Ind. Eng. Progress 2008, 27 (7), 963-967.

(10) Li, X. S.; Xu, C. G.; Chen, Z. Y.; Wu, H. J. Hydrate-based precombustion carbon dioxide capture process in the system with tetra-nbutyl ammonium bromide solution in the presence of cyclopentane. Energy 2011, 36 (3), 1394-1403.

(11) Zhang, Y.; Wu, H. J.; Li, X. S.; Chen, Z. Y.; Li, G.; Zeng, Z. Y. Dissociation behavior of methane hydrate in porous media. Chem. J. Chin. Univ. 2010, 31 (9), 1848-1854.

(12) Li, X. S.; Xu, C. G.; Chen, Z. Y.; Wu, H. J. Tetra-n-butyl ammonium bromide semi-clathrate hydrate process for postcombustion capture of carbon dioxide in the presence of dodecyl trimethyl ammonium chloride. Energy 2010, 35 (9), 3902-3908.

(13) Li, X. S.; Xia, Z. M.; Chen, Z. Y.; Yan, K. F.; Li, G.; Wu, H. J. Equilibrium hydrate formation conditions for the mixtures of $\mathrm{CO}(2)+$ $\mathrm{H}(2)+$ tetrabutyl ammonium bromide. J. Chem. Eng. Data 2010, 55 (6), 2180-2184.

(14) Li, X. S.; Xia, Z. M.; Chen, Z. Y.; Yan, K. F.; Li, G.; Wu, H. J. Gas hydrate formation process for capture of carbon dioxide from fuel gas mixture. Ind. Eng. Chem. Res. 2010, 49 (22), 11614-11619.

(15) Kang, S. P.; Lee, H. Recovery of $\mathrm{CO}_{2}$ from Flue Gas Using Gas Hydrate: Thermodynamic Verification through Phase Equilibrium Measurements. Environ. Sci. Technol. 2000, 34 (20), 4397-4400.

(16) Klara, S. M.; Srivastava, R. D. U.S. DOE integrated collaborative technology development program for $\mathrm{CO}_{2}$ separation and capture. Environ. Progr. 2002, 21 (4), 247-253.

(17) Linga, P.; Kumar, R.; Englezos, P. The clathrate hydrate process for post and pre-combustion capture of carbon dioxide. J. Hazard. Mater. 2007, 149 (3), 625-629.

(18) Linga, P.; Kumar, R.; Englezos, P. Gas hydrate formation from hydrogen/carbon dioxide and nitrogen/carbon dioxide gas mixtures. Chem. Eng. Sci. 2007, 62 (16), 4268-4276.

(19) Happel, J.; Hnatow, M. A.; Meyer, H. The study of separation of nitrogen from methane by hydrate formation using a novel apparatus. International Conference on Natural Gas Hydrates, New York, June 2024, 1994; Vol. 715, pp 412-424.

(20) Xu, F.; Wu, Q.; Zhu, L. H. Fractal-like Kinetic Characteristics of Coalbed Methane Hydrate Dissociation at Normal Pressure. Chin. J. Chem. 2011, 29 (1), 21-26.
(21) Zhao, J. Z.; Zhen, Y. S.; Shi, D. X. Experiment on methane concentration from oxygen-containing coal bed gas by THF solution hydrate formation. J. Chin. Coal Soc. 2008, 33 (12), 1419-1424.

(22) Zhang, B. Y.; Wu, Q. Thermodynamic promotion of tetrahydrofuran on methane separation from low-concentration coal mine methane based on hydrate. Energy Fuels 2010, 24, 2530-2535.

(23) Sun, Q.; X., G.; Liu, A. X.; et al. Experimental study on the separation of $\mathrm{CH}_{4}$ and $\mathrm{N}_{2}$ via hydrate formation in $\mathrm{TBAB}$ solution. Ind. Eng. Chem. Res. 2011, 50, 2284-2288.

(24) Wu, Q.; He, X. Q.; Zhang, B. Y.; Wang, Y. J. Thermodynamic effect of surfactant on gas hydrate formation. J. Chem. Ind. Eng. (Chin.) 2006, 57 (12), 2793-2797.

(25) Zhang, B. Y.; Wu, Q. Dynamic Effect of Surfactant on Gas Hydrate Formation Process. J. Chin. Univ. Mining Technol. 2007, 36 (4), 478-481.

(26) Feng, X.; WU, Q.; Zhang, B. Y. Study on Storage and Transportation of Coalbed Methane Based on Hydrate Technology. Gas Heat 2008, 28 (6), 39-43.

(27) Adisasmito, S.; Frank, R. J.; Sloan, E. D. Hydrates of carbondioxide and methane mixtures. J. Chem. Eng. Data 1991, 36 (1), $68-$ 71.

(28) Vancleeff, A.; Diepen, G. A. M. Gas hydrates of nitrogen and oxygen. Recueil Des Travaux Chimiques Des Pays-Bas-J. R. Netherlands Chem. Soc. 1960, 79 (5), 582-586.

(29) Jhaveri, J.; Robinson, D. B. Hydrates in methane-nitrogen system. Can. J. Chem. Eng. 1965, 43 (2), 75-\&.

(30) Smith, J. M.; Van Ness, H. C.; Abbott, M. M. Introduction to chemical engineering thermodynamics; McGraw-Hill: New York, 2001.

(31) Cai, J.; Chen, Z. Y.; Li, X. S.; Xu, C. G., Separation and purification of methane from coal-bed methane via the hydrate technology. In 2010 International Conference on Energy and Environment Technology, 2010 International Conference on Digital Manufacturing \& Automation, Changsha, China, Dec. 18-20, 2010; Vol. 2, pp $341-345$.

(32) Englezos, P.; Linga, P.; Adeyemo, A. Medium-pressure clathrate hydrate/membrane hybrid process for postcombustion capture of carbon dioxide. Environ. Sci. Technol. 2008, 42 (1), 315-320.

(33) Lee, J. D.; Susilo, R.; Englezos, P. Kinetics of structure H gas hydrate. Energy Fuels 2005, 19 (3), 1008-1015.

(34) Linga, P.; Kumar, R.; Lee, J. D.; Ripmeester, J.; Englezos, P. A new apparatus to enhance the rate of gas hydrate formation: Application to capture of carbon dioxide. Int. J. Greenhouse Gas Control 2010, 4 (4), 630-637.

(35) Zhong, Y.; Rogers, R. E. Surfactant effects on gas hydrate formation. Chem. Eng. Sci. 2000, 55 (19), 4175-4187.

(36) Sun, Z. G.; Wang, R. Z.; Ma, R. S.; Guo, K. H.; Fan, S. S. Natural gas storage in hydrates with the presence of promoters. Energy Conver. Manage. 2003, 44 (17), 2733-2742.

(37) Lee, J. W.; Zhang, J. S.; Lo, C.; Somasundaran, P. Competitive adsorption between SDS and carbonate on tetrahydrofuran hydrates. $J$. Colloid Interface Sci. 2010, 341 (2), 286-288.

(38) Kim, S. M.; Lee, J. D.; Lee, H. J.; Lee, E. K.; Kim, Y. Gas hydrate formation method to capture the carbon dioxide for pre-combustion process in IGCC plant. Int. J. Hydrogen Energy 2011, 36, 1115-1121. 